\title{
Determination of eight artificial sweeteners and common Stevia rebaudiana glycosides in non-alcoholic and alcoholic beverages by reversed-phase liquid chromatography coupled with tandem mass spectrometry
}

\author{
Paweł Kubica • Jacek Namieśnik • Andrzej Wasik
}

Received: 7 October 2014 /Revised: 12 November 2014 / Accepted: 17 November 2014 / Published online: 4 December 2014

(C) The Author(s) 2014. This article is published with open access at Springerlink.com

\begin{abstract}
The method for the determination of acesulfame-K, saccharine, cyclamate, aspartame, sucralose, alitame, neohesperidin dihydrochalcone, neotame and five common steviol glycosides (rebaudioside A, rebaudioside C, steviol, steviolbioside and stevioside) in soft and alcoholic beverages was developed using high-performance liquid chromatography and tandem mass spectrometry with electrospray ionisation (HPLC-ESI-MS/MS). To the best of our knowledge, this is the first work that presents an HPLC-ESI-MS/MS method which allows for the simultaneous determination of all EU-authorised high-potency sweeteners (thaumatin being the only exception) in one analytical run. The minimalistic sample preparation procedure consisted of only two operations; dilution and centrifugation. Linearity, limits of detection and quantitation, repeatability, and trueness of the method were evaluated. The obtained recoveries at three tested concentration levels varied from 97.0 to $105.7 \%$, with relative standard deviations lower than $4.1 \%$. The proposed method was successfully applied for the determination of sweeteners in 24 samples of different soft and alcoholic drinks.
\end{abstract}

Keywords Artificial sweeteners $\cdot$ Steviol glycosides $\cdot$ Stevia rebaudiana $\cdot$ Tandem mass spectrometry $\cdot$ Liquid chromatography

Electronic supplementary material The online version of this article (doi:10.1007/s00216-014-8355-x) contains supplementary material, which is available to authorized users.

P. Kubica · J. Namieśnik · A. Wasik $(\square)$

Department of Analytical Chemistry, Faculty of Chemistry, Gdańsk

University of Technology, Narutowicza 11/12, 80-233 Gdańsk,

Poland

e-mail: wasia@pg.gda.pl

\section{Introduction}

Sweetness is probably one of the most appreciated features of the food we eat. However, not all consumers want to (or can) consume sugars - the most obvious source of sweetness. The artificial sweeteners which are commonly used in the food industry seem to be an ideal, non-caloric replacement for sweet-tasting sugars.

These sweeteners and their mixtures play an important role in the modern food industry since they provide a means to fulfil the consumer's demand for sweet, tooth-friendly, reduced-calorie food. The newest members of the European Union (EU)-authorised sweeteners' family are steviol glycosides. The leaves of Stevia contain mostly stevioside and rebaudioside $\mathrm{A}$. Other glycosides present include rebaudioside $\mathrm{C}$, dulcoside $\mathrm{A}$, steviolbioside, rubusoside and rebaudiosides D, E and F [1, 2]. Rebaudioside A is the most desired component of Stevia leaf extracts, due to its highest sweetening potency and the least pronounced bitter aftertaste. Steviol glycosides are the second completely natural EUauthorised sweeteners, thaumatin being the first.

While the demand for sweetness without calories is continuously growing, there are still controversies concerning the safety of high-potency sweeteners. Therefore, to ensure consumer safety and trust, the content of such sweeteners in food is strictly regulated by regional or national legislation [3-7]. Proper control over food manufacturing processes calls for appropriate analytical methods, capable of providing reliable results when analysing food samples, usually characterised by quite a complex matrix.

Among all the available methods for the determination of artificial sweeteners in foodstuffs, reversed-phase high-performance liquid chromatography (RP-HPLC) coupled with a variety of detectors is probably the most popular choice [8]. Nowadays, RP-HPLC coupled with tandem mass 
spectrometry is becoming more and more popular due to its high selectivity and multianalyte capability [9-14], which is an important feature since different sweeteners are frequently used in mixtures to achieve the desired taste, flavour or texture of an end product. Methods capable of separating and quantifying multiple high-potency sweeteners in foods are known $[8,10,15-29]$, but, to the best of our knowledge, their ability to determine Stevia-based sweeteners in mixtures with other non-caloric sweeteners was not yet demonstrated in practice.

The purpose of this project was to develop a quick, simple and robust method for the determination of almost all EUauthorised high-potency sweeteners, including steviol glycosides. The only exception is thaumatin which is a protein and cannot be quantified with this method due to the incompatibility with the separation conditions used. According to the proposed method, analytes are separated by RP-HPLC, and later on detected and quantified using tandem mass spectrometry. The sample preparation procedure is limited to the dilution and centrifugation (or filtration) of the samples. The method allows the quantification of 14 compounds in one 16-min-long analytical run. Low values of limits of quantitation (LOQ), high recoveries, and satisfactory repeatability make it suitable for application in food control laboratories, as demonstrated by the analysis of 24 samples of different soft and alcoholic beverages.

\section{Materials and methods}

\section{Chemicals}

Standards of artificial sweeteners and steviol glycosides were obtained from different sources: acesulfame-K from Nutrinova (Frankfurt am Main, Germany); saccharine, sucralose and neohesperidin DC from Sigma-Aldrich (St. Louis, USA); aspartame from Ajinomoto Foods Europe (Nesle, France); cyclamate from Merck KGaA (Darmstadt, Germany); alitame from Frapp's Pharma (Hong Kong, China); neotame from CHEMOS (Regenstauf, Germany); and rebaudioside $\mathrm{A}$, stevioside, rebaudioside $\mathrm{C}$, dulcoside $\mathrm{A}$, steviolbioside and steviol from LGC Standards (Lomianki, Poland). As the internal standard (IS), sodium $\mathrm{N}$-(2methylcyclohexyl)sulfamate was used [27]. Acetonitrile $(\mathrm{ACN})$, methanol $(\mathrm{MeOH})$ and acetone were purchased from Merck KGaA (Darmstadt, Germany). Acetic acid (AA) was obtained from POCH (Gliwice, Poland). Ultrapure water was prepared using the HLP5 system from Hydrolab (Wiślina, Poland).

\section{Samples}

Twenty-one samples of popular soft and alcoholic drinks and three samples of instant drink powders from different producers were purchased in local shops. Most products were labelled as containing steviol glycosides, although other drinks were also included for method-testing purposes.

Preparation of standards and calibration solutions

The stock solutions of acesulfame-K, saccharine, neohesperidin DC, aspartame, sucralose, cyclamate, alitame, neotame, rebaudioside A, stevioside, rebaudioside $\mathrm{C}$, dulcoside $\mathrm{A}$, steviolbioside and steviol were prepared by dissolving the appropriate amount of pure standard in the mixture of $\mathrm{ACN}$ and $\mathrm{H}_{2} \mathrm{O}(60+40)$. The final concentration of each standard was around $50 \mu \mathrm{g} / \mathrm{mL}$. The calibration solutions were prepared by mixing and diluting the stock solutions with the mobilephase component A to obtain 5, 20, 50, 100, 200, 400 and $800 \mathrm{ng} / \mathrm{mL}$ of acesulfame-K, saccharin, neohesperidin DC, aspartame, sucralose, cyclamate, alitame and neotame, while concentrations of rebaudioside A, stevioside, rebaudioside $\mathrm{C}$, dulcoside $\mathrm{A}$, steviolbioside and steviol were 5, 20, 100, 300, 600, 1000 and $1600 \mathrm{ng} / \mathrm{mL}$, respectively. The IS concentration was kept at $50 \mathrm{ng} / \mathrm{mL}$ in each calibration solution. All solutions were stored in a refrigerator at $4{ }^{\circ} \mathrm{C}$; new solutions were prepared monthly.

\section{Sample preparation and fortification procedures}

Before sample preparation, all samples of soft and alcoholic drinks were degassed by sonication for $15 \mathrm{~min}$. Instant drinks were prepared according to the manufacturer's directions. Samples were diluted with mobile-phase component A in order to fall within calibration curve concentration range. In practice, a hundred times of dilution was appropriate, i.e. $100 \mu \mathrm{L}$ of each sample and $50 \mu \mathrm{L}$ of IS solution were placed in a $10-\mathrm{mL}$ volumetric flask and filled up to the mark. Approximately $1.5 \mathrm{~mL}$ of this solution was placed in an Eppendorf tube and centrifuged for $5 \mathrm{~min}$ at $7000 \mathrm{rpm}$. Supernatant was collected, placed in the autosampler vial and analysed.

Fortified samples (three concentration levels) were prepared using the Sprite ${ }^{\mathrm{TM}}$ drink (old recipe, free from steviol glycosides and other high-potency sweeteners) as a matrix. Sweeteners were dissolved in Sprite ${ }^{\mathrm{TM}}$ to get a concentration of $500 \mu \mathrm{g} / \mathrm{mL}$ each. This mixture was later on diluted with Sprite $^{\mathrm{TM}}$ to obtain the concentration levels of 10,25 and $60 \mu \mathrm{g} / \mathrm{mL}$. Fortified samples were used for repeatability and apparent recovery estimation.

MS/MS conditions

All analyses were done using a Shimadzu LCMS-8050 triple quadrupole mass spectrometer (Shimadzu, Japan) 
equipped with an ESI source working in the polarityswitching MRM mode. Positive detection mode for aspartame, alitame and neotame was selected to increase the sensitivity. Data acquisition and analysis were accomplished with LabSolutions 5.60 SP1 software. The specific MRM transitions were chosen in the flow injection mode. The optimum detection conditions are presented in Table S1 in the Electronic Supplementary Material (ESM).

\section{HPLC conditions}

The chromatographic separation was carried out using an HPLC system (Shimadzu, Japan) consisting of a degasser DGU-20A5R, controller CBM-20A, binary pump Nexera X2 LC-30 AD, autosampler Nexera X2 SIL-30AC and column oven CTO-20AC. The analytes were separated on an Ascentis Express C18 column (Supelco, Belefonte, PA, $100 \mathrm{~mm} \times 4.6 \mathrm{~mm}, 2.7 \mu \mathrm{m}$ ). The temperature of the column oven was set to $40{ }^{\circ} \mathrm{C}$, the flow rate was kept at $0.8 \mathrm{~mL} / \mathrm{min}$ and the injection volume was set to $2 \mu \mathrm{L}$. The mobile phase used for the separation was $\mathrm{H}_{2} \mathrm{O}+\mathrm{MeOH}+$ acetone $(75+20+5)$ with $0.1 \% v / v$ of $\mathrm{AA}$ (component $\mathrm{A}$ ) and $\mathrm{ACN}+$ acetone $(95+5)$ with $0.1 \% v / v$ of AA (component B). The chromatographic separation was performed in gradient elution mode: $0 \mathrm{~min}(0 \% \mathrm{~B}), 10 \mathrm{~min}(30 \% \mathrm{~B}), 15 \mathrm{~min}$ $(70 \% \mathrm{~B})$ and $16 \mathrm{~min}(70 \% \mathrm{~B})$. The total time of the chromatographic run was $16 \mathrm{~min}$, while the column equilibration time was set to $8 \mathrm{~min}$. The chromatogram presenting the separation of analytes is shown in Fig. 1.

\section{Results and discussion}

Separation and detection of analytes

In case of sucralose, acetic acid adduct was chosen $(454.85 \mathrm{~m} / \mathrm{z})$ as the parent ion and 395.05 as the fragment ion. The choice was dictated by the fact that the intensity of this transition $(454.85 \rightarrow 395.05)$ was higher than the transition of the pseudomolecular ion of sucralose (395.05) to its fragments: 359.15 or 87.05 . The fragmentation of steviol molecule was not observed neither in negative nor in positive mode. The higher intensity of the pseudomolecular ion was higher in the negative mode. The absence of fragment ions forced the choice of pseudotransition of steviol $317.40 \rightarrow 317.40$. The best response for aspartame, alitame and neotame was observed in the positive mode of detection.

The addition of a small amount of acetone to both components of the mobile phase resulted in narrower peaks for acesulfame-K, saccharin, aspartame, sucralose, cyclamate, alitame, neohesperidin DC and neotame. The change of peak shapes for rebaudioside A, stevioside, rebaudioside $\mathrm{C}$, dulcoside, steviolbioside and steviol was not observed regardless of acetone addition. Use of two organic components in mobile phase (ACN and $\mathrm{MeOH})$ resulted in better separation of analytes in comparison to the separation achieved with only one organic component. Methanol-only mobile phase had not enough eluting strength to achieve separation in less than $25 \mathrm{~min}$; an incomplete separation of rebaudioside A and stevioside was observed as well. On the other hand, acetonitrile-only mobile phase had higher elution power, but an incomplete separation of acesulfame-K and saccharin, sucralose and cyclamate, and rebaudioside $\mathrm{A}$ and stevioside was noticed. The combination of methanol in mobile-phase component $\mathrm{A}$ and acetonitrile in mobile-phase component $\mathrm{B}$ resulted in a complete separation of these compounds, relatively short analysis time and better separation of rebaudioside $\mathrm{A}$ and stevioside. A complete separation was achieved for most of the compounds, except reabudioside $\mathrm{A}$ and stevioside $\left(R_{\mathrm{S}}=1.2\right)$. This was caused by fact that these two compounds differ only by one extra glucose molecule in the structure of RA. However, complete separation is not necessary in that case, since two specific transitions for RA and SV, respectively, can be measured independently.

\section{Within-laboratory validation}

\section{Calibration}

Seven-point calibration curves were constructed by plotting the ratio of the analyte's peak area to the peak area of the IS versus the analyte's concentration $(n=3)$. Different concentration ranges were used for two different classes of sweeteners: 5-800 $\mathrm{ng} / \mathrm{mL}$ for the artificial ones and 5-1600 ng/mL for steviol glycosides. Calibration curves were linear in the studied concentration range with correlation coefficients of over 0.9987 . The weighing factor of $1 / x$ was applied to all calibration curves in order to increase the accuracy in the lower concentration range. The values of limit of detection (LOD) were calculated using the following formula: $\mathrm{LOD}=3.3 \cdot S_{b} / a$, where $S_{b}$ is the standard deviation of the intercept and $a$ is the slope of the calibration curve. The values of limit of quantitation (LOQ) were calculated as three times LOD. Quantification limits were between 3.23 and $13.56 \mathrm{ng} / \mathrm{mL}$, which correspond to the range of 0.323 and $1.36 \mathrm{mg} / \mathrm{L}$ in the original sample, assuming a hundred times of dilution of the sample. These values are well below the regulatory limits for all 
Fig. 1 Example of a chromatogram of standard mixture (200 ng/mL each) - see conditions in the text

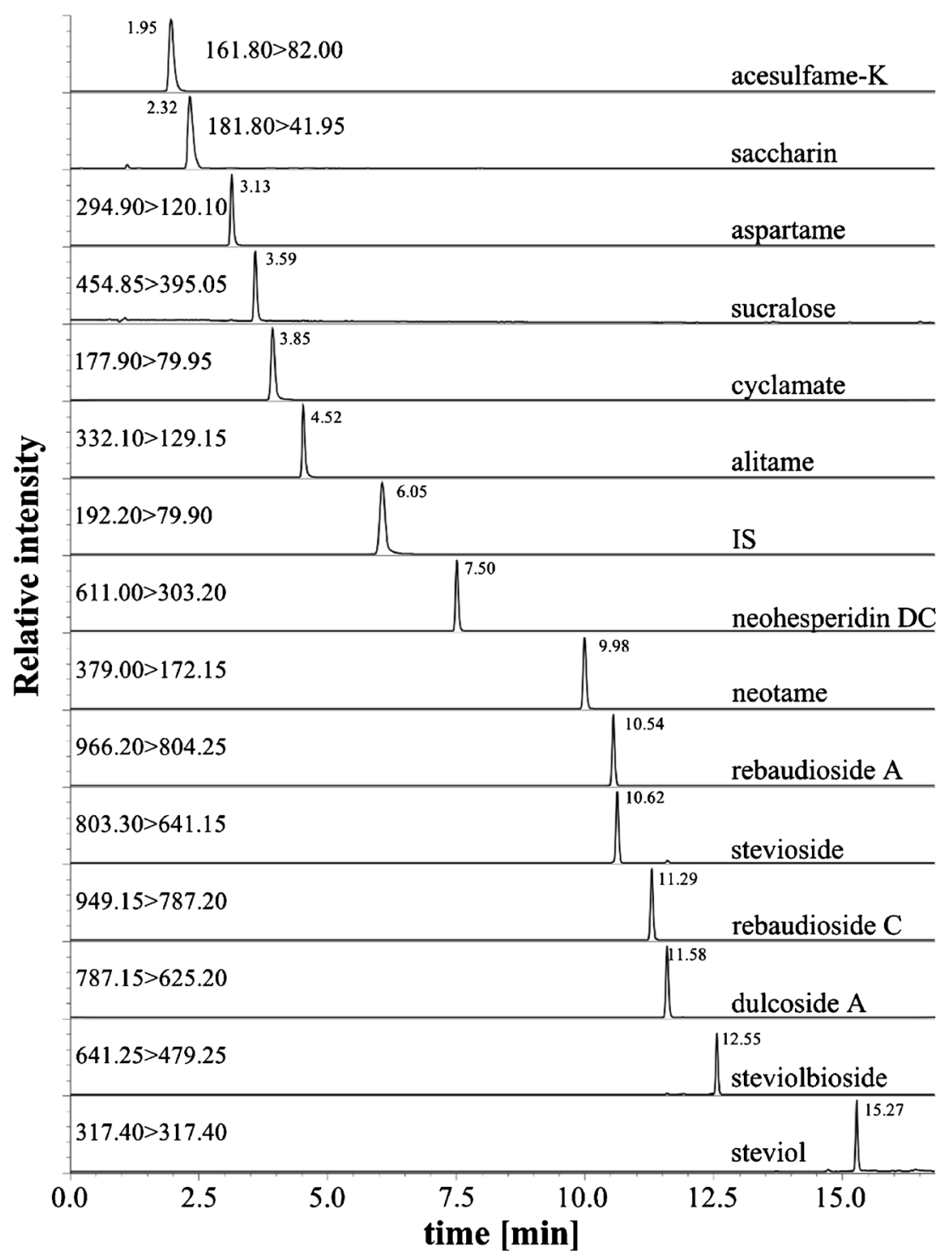

compounds under the study. The values of calibration parameters are presented in Table 1.

\section{Trueness and repeatability}

The trueness of the results was assessed in terms of apparent recoveries using spiked Sprite ${ }^{\mathrm{TM}}$ drink as a matrix. Samples spiked at three concentration levels $(10,25$ and $60 \mu \mathrm{g} / \mathrm{mL})$ were analysed on the same day (six replicates of each concentration level). Recoveries varied between 97.0 and $105.7 \%$, while the relative standard deviations (\%RSD) of the results were in the range of $0.4-4.1 \%$. The recovery data and \%RSD values indicate good method accuracy and precision. No matrix effects were observed, thanks to the use of an internal standard, significant dilution of the samples and complete separation of analytes.
Repeatability, expressed as between-day precision during the next three consecutive days, was estimated by analysing a set of samples $(n=6)$ spiked at one concentration level $(600 \mathrm{ng} / \mathrm{mL}$ after sample preparation step). The $\%$ RSD of the results were in the range of $1.1-4.5 \%$, very close to the within-day precision. This demonstrates that the method provides consistent, dayby-day results. Detailed data concerning trueness and repeatability are presented in ESM Table S2.

Analysis of real samples

Samples were bought in local shops, and attention was paid to ensure their diversity. Three types of drinks were analysed: non-carbonated and carbonated soft drinks, and carbonated alcoholic beverages (beers). Most of the samples (18) were labelled as containing steviol glycosides, though beverages sweetened with other 
Table 1 Quantification and validation data for artificial sweeteners and steviol glycosides

\begin{tabular}{|c|c|c|c|c|c|c|}
\hline Analyte & $\begin{array}{l}\text { Calibration curve equation } \\
\text { ( } 7 \text { points, } n=3 \text { ) }\end{array}$ & $S_{a}$ & $S_{b}$ & $r$ & $\begin{array}{l}\mathrm{LOD} \\
{[\mathrm{ng} / \mathrm{mL}]}\end{array}$ & $\begin{array}{l}\text { LOQ } \\
{[\mathrm{ng} / \mathrm{mL}]}\end{array}$ \\
\hline Acesulfame-K & $y=0.04286 x+0.099$ & 0.00079 & 0.059 & 0.9987 & 4.52 & 13.56 \\
\hline Saccharin & $y=0.004583 x+0.0025$ & 0.000025 & 0.0018 & 0.9997 & 1.32 & 3.95 \\
\hline Aspartame & $y=0.04189 x-0.070$ & 0.00028 & 0.021 & 0.9996 & 1.63 & 4.90 \\
\hline Sucralose & $y=0.010964 x-0.0158$ & 0.000062 & 0.0046 & 0.9997 & 1.38 & 4.14 \\
\hline Cyclamate & $y=0.02994 x-0.0454$ & 0.00013 & 0.0098 & 0.9998 & 1.08 & 3.23 \\
\hline Alitame & $y=0.02816 x-0.024$ & 0.00021 & 0.015 & 0.9994 & 1.78 & 5.35 \\
\hline Neohesperidin DC & $y=0.04840 x-0.124$ & 0.00045 & 0.033 & 0.9991 & 2.28 & 6.84 \\
\hline Neotame & $y=0.004872 x-0.0012$ & 0.000020 & 0.0029 & 0.9998 & 1.98 & 5.95 \\
\hline Rebaudioside A & $y=0.004625 x-0.0005$ & 0.000019 & 0.0029 & 0.9998 & 2.04 & 6.11 \\
\hline Stevioside & $y=0.016005 x-0.011$ & 0.000071 & 0.010 & 0.9998 & 2.16 & 6.48 \\
\hline Rebaudioside C & $y=0.007403 x-0.0168$ & 0.000035 & 0.0052 & 0.9997 & 2.33 & 7.00 \\
\hline Dulcoside A & $y=0.002522 x+0.0022$ & 0.000014 & 0.0021 & 0.9997 & 2.69 & 8.08 \\
\hline Steviolbioside & $y=0.05032 x+0.131$ & 0.00028 & 0.042 & 0.9997 & 2.74 & 8.23 \\
\hline Steviol & $y=0.011370 x-0.0362$ & 0.000095 & 0.0070 & 0.9993 & 2.04 & 6.12 \\
\hline
\end{tabular}

$S_{a}$ standard deviation of the slope, $S_{b}$ standard deviation of the intercept, $r$ correlation coefficient, $L O D$ limit of detection, $L O Q$ limit of quantitation, $n$ number of measurements

compounds were also taken into account. According to the regulations $[5,6]$, the content of steviol glycosides should be expressed as the sum of steviol equivalents. The equivalents of steviol are calculated for each glycoside separately using the following multiplication factors: steviol (1.000), stevioside (0.395), rebaudioside A (0.329), rebaudioside C (0.334), dulcoside A (0.400) and steviolbioside (0.496). For the majority of tested samples, the sum of steviol equivalents was within the acceptable limit $(60 \mathrm{mg} / \mathrm{L})$ - see Table 2 for details. In two cases (NCNA4 and NCNA8), the legal limit was exceeded.

Stevia-based sweeteners used in the food industry differ in terms of their composition. Four out of 18 samples were sweetened with highly purified rebaudioside A, and 6 contained rebaudioside A and stevioside. Also, in six cases, three steviol glycosides (rebaudioside A, stevioside, rebaudioside $\mathrm{C}$ ) were found, and two samples contained four glycosides (rebaudioside A, stevioside, rebaudioside $\mathrm{C}$ and steviolbioside). The major compound found in the samples containing a mixture of steviol glycosides was rebaudioside $\mathrm{A}$, the rest being stevioside and, in some cases, minor amounts of rebaudioside $\mathrm{C}$ and steviolbioside.

Beverages sweetened with steviol glycosides were found free from other high-potency sweeteners. However, in three cases (CNA1, CNA4 and NCNA4), small amounts of neohesperidin DC were detected. The labels of these beverages did not mention any sweetener other than steviol glycosides, but since neohesperidin DC at low concentrations (up to $3 \mathrm{mg} / \mathrm{kg}$ ) may be used as a flavour enhancer [7], the composition of these samples is in accordance with the law.

Two out of the five analysed beer samples (CA4 and CA5) were sweetened with artificial high-potency sweeteners. Mixtures of two and four compounds were detected in these cases.

Detailed results of the analysis of all samples are presented in Table 2, and examples of real chromatograms are presented in Fig. 2.

\section{Conclusions}

The presented method allows for the quick determination of all but one EU-authorised high-potency sweeteners in one analytical run. The sample preparation step was simplified to an absolute minimum. It consisted of only two operations: the dilution and centrifugation (or filtration) of the samples. Thanks to the complete separation of analytes and considerable dilution of the analysed samples, no matrix effects were observed. Since the method allows the separation and quantifying of common steviol glycosides, being the components of commercially available Stevia-based sweeteners, it can be used to determine their purity/quality. Low limits of quantification, high recoveries and good repeatability of results make it suitable for food quality and safety control. The method was successfully applied for the analysis of sweeteners in alcoholic 


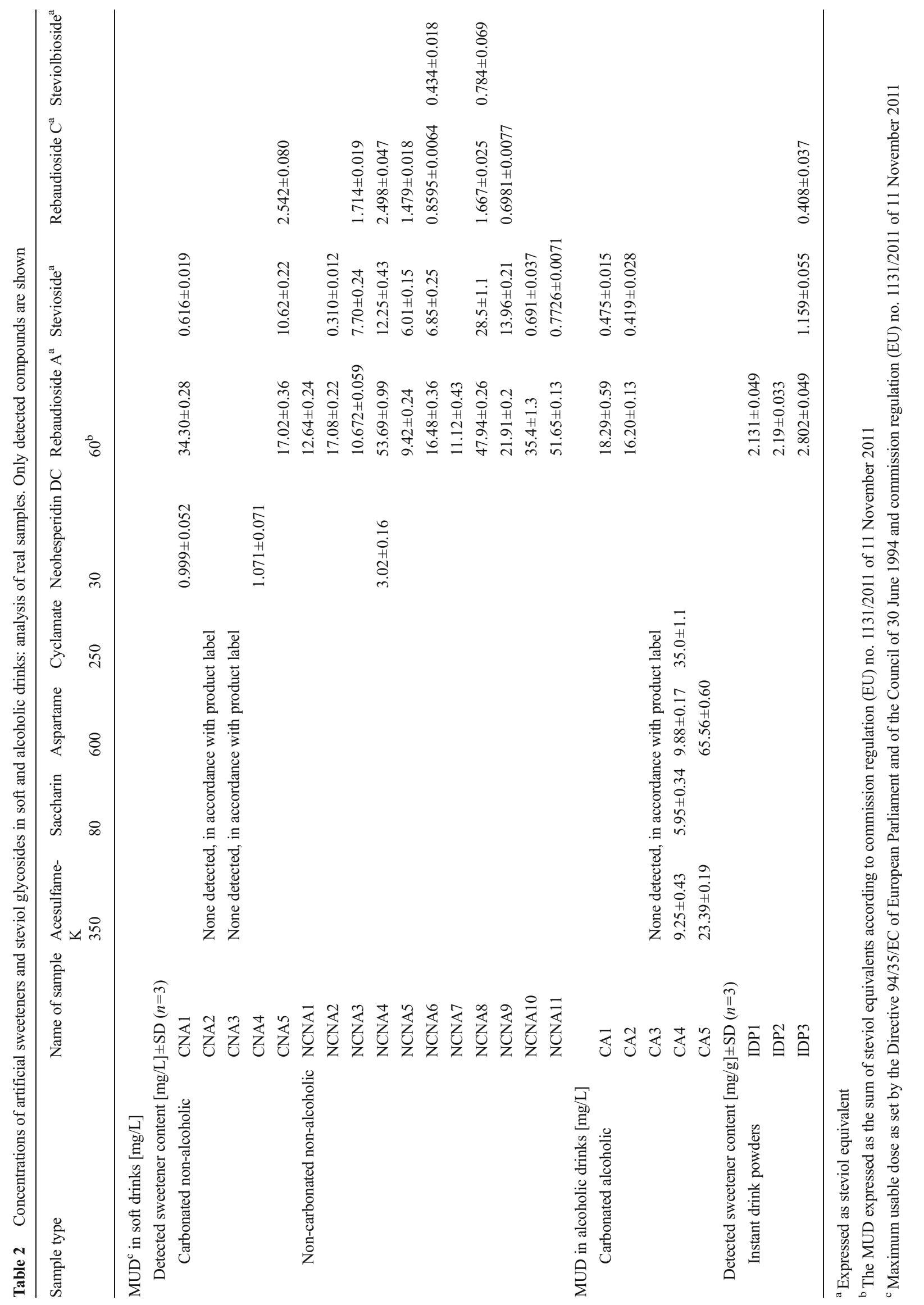


Fig. 2 Examples of chromatograms obtained for real samples. From the top: A sample of CNA1, B sample of NCNA6 and $\mathbf{C}$ sample of CA4

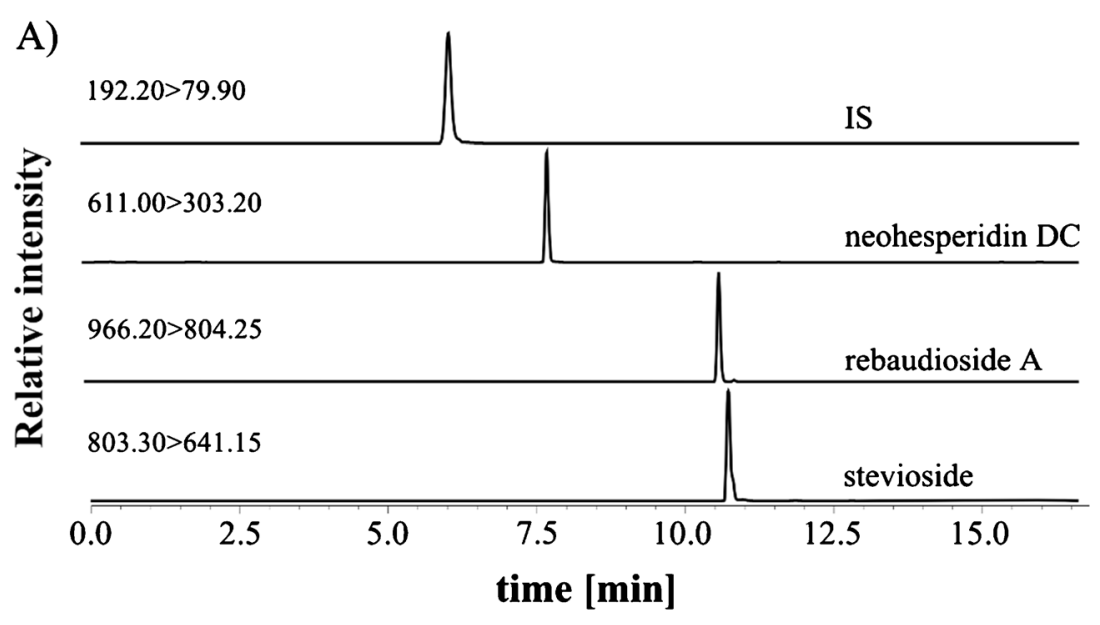

B)

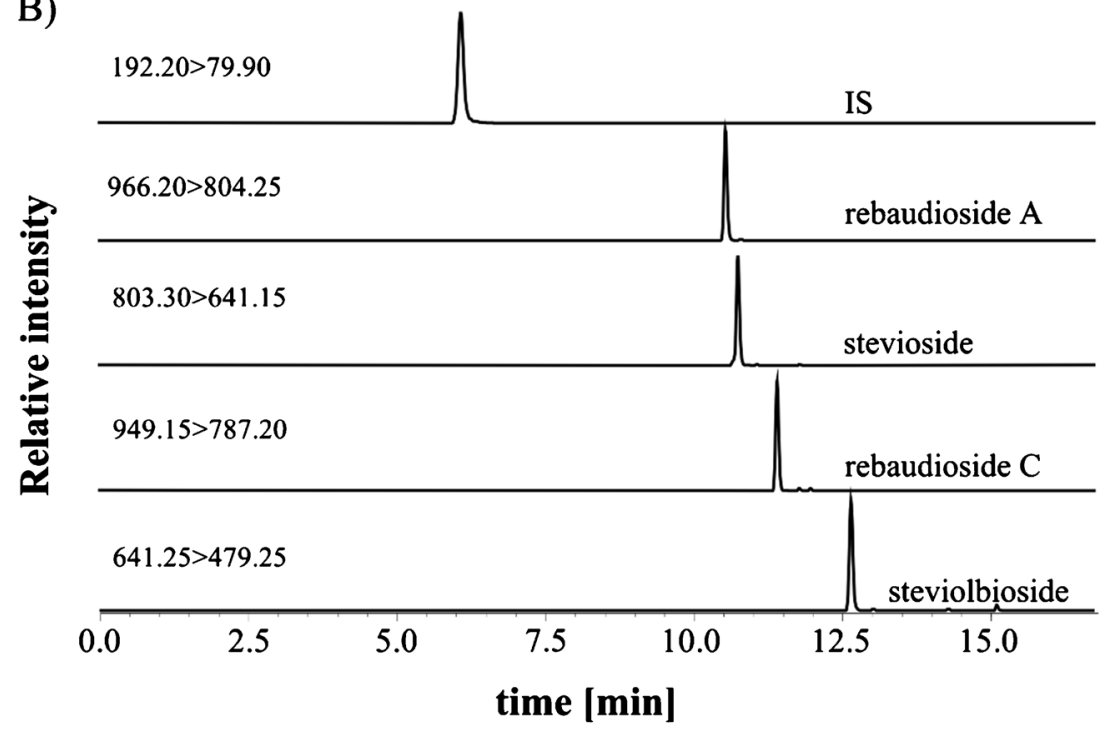

C) $161.80>82.00$ acesulfame-K

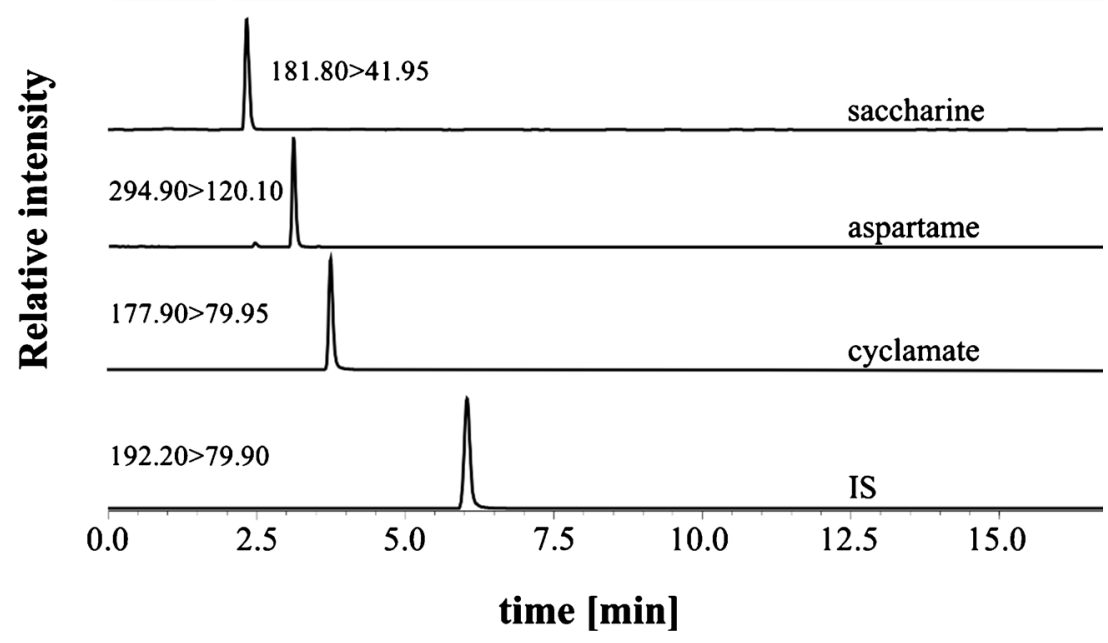


and non-alcoholic beverages. To the best of our knowledge, this is the first method which allows for the comprehensive analysis of beverages with regard to high-potency sweetener content, including the recently introduced steviol glycosides.

Acknowledgments The authors would like to thank Andrzej Reszka and Marcin Gawryś (Shim-Pol, Poland) for providing the LCMS-8050 instrument. This work has been financially supported by a Polish National Science Centre grant (research project no. 2012/07/N/ST4/01834). Pawel Kubica acknowledges the grant awarded by PSEZ (Pomeranian Special Economic Zone Ltd.). The authors would like to thank Barbara Sobieszek for her great support.

Open Access This article is distributed under the terms of the Creative Commons Attribution License which permits any use, distribution, and reproduction in any medium, provided the original author(s) and the source are credited.

\section{References}

1. Stevia - a non-caloric sweetener of natural origin (2012) Institute of Food Science and Technology, London. http://www.ifst.org/print/ 130. Accessed 2 October 2014

2. Jackson AU, Tata A, Wu C, Perry RH, Haas G, West L, Cooks RG (2009) Analyst 134:867

3. European Parliament and Council Directive 94/35/EC of 30 June 1994 on sweeteners for use in foodstuffs L237/13 (1994) OJ 237:3

4. Commission Directive 2009/163/EU of 22 December amending Directive 94/35/EC of the European Parliament and of the Council on sweeteners for use in foodstuffs with regard to neotame (2009) L344:37

5. Regulation of the Polish Minister of Health of 22 November 2010 on the permitted additives (2010) 177:1094

6. Commission Regulation (EU) No 1131/2011 of 11 November 2011 amending Annex II to Regulation (EC) No 1333/2008 of the European Parliament and of the Council with regard to steviol glycosides (2011) L295:205
7. Commision Implementing Regulation (EU) No 872/2012 of 1 October 2012 adopting the list of flavouring substances provided for by Regulation (EC) No 2232/96 of the European Parliament and of the Council, introducing it in Annex I to Regulation (EC) No $1334 / 2008$ of the European Parliament and of the Council and repealing Commission Regulation (EC) No 1565/2000 and Commission Decision 1999/217/EC (2012) L267:1

8. Wasik A, Namieśnik J (2009) TrAC Trends Anal Chem 28:1082

9. Berset J-D, Ochsenbein N (2012) Chemosphere 88:563

10. Chen X-H, Zhao Y-G, Shen H-Y, Jin M-C (2012) J Chromatogr A 1263:34

11. Gan Z, Sun H, Wang R, Feng B (2013) J Chromatogr A 1274:87

12. Loos R, Gawlik BM, Boettcher K, Locoro G, Contini S, Bidoglio G (2009) J Chromatogr A 1216:1126

13. Ordónez EY, Quintana JB, Rodil R, Cela R (2012) J Chromatogr A 1256:197

14. Scheurer M, Brauch H-J, Lange FT (2009) Anal Bioanal Chem 394: 1585

15. Bergamo AB, Silva JAF, Jesus DP (2011) Food Chem 2011:1714

16. Croitoru MD, Fülöp I, Ajtay MK, Balogh C, Dogaru MT (2011) Acta Aliment Hung 40:459

17. Ferrer I, Thurman EM (2010) J Chromatogr A 1217:4127

18. Huang Z, Mab J, Chen B, Zhang Y, Yao S (2006) Anal Chim Acta $555: 233$

19. Llamas NE, Nezio MSD, Palomeque ME, Band BSF (2008) Food Anal Method 1:43

20. Lorenzo RA, Pena MT, Fernández P, Gonzáleza PP, Carro AM (2015) Food Control 47:43

21. Nazareth V, Fernandes O, Fernandes LB, Vasconcellos JP, Jager AV, Tonin FG, Oliveira MAL (2013) Anal Methods 5:1524

22. Qing-Chuan, Wang J (2001) J Chromatogr A 937:57

23. Stojkovic M, Mai TD, Hauser PC (2013) Anal Chim Acta 787:254

24. Wasik A, McCourt J, Buchgraber M (2007) J Chromatogr A 1157: 187

25. Yang D-J, Chen B (2009) J Agr Food Chem 57:3022

26. Zhu Y, Guo Y, Ye M, James FS (2005) J Chromatogr A 1085:143

27. Zygler A, Wasik A, Kot-Wasik A, Namieśnik J (2011) Anal Bioanal Chem 400:2159

28. Zygler A, Wasik A, Kot-Wasik A, Namieśnik J (2012) Food Addit Contam A 29:1391

29. Zygler A, Wasik A, Namieśnik J (2010) Talanta 82:1742 